\begin{tabular}{llll}
\hline Submission: $09 / 08 / 2020 ;$ & $1^{\text {st }}$ round notif.: $13 / 10 / 2020 ;$ & New version: $26 / 10 / 2020 ;$ & $2^{\text {nd }}$ round notif.: $12 / 11 / 2020 ;$ \\
Camera ready: $13 / 12 / 2020 ;$ & Edition review: $14 / 12 / 2020 ;$ & Available online: $15 / 12 / 2020 ;$ & Published: $15 / 12 / 2020 ;$
\end{tabular}

\title{
Neoliberalismo e crise: $o$ avanço silencioso do capitalismo de vigilância na educação brasileira durante a pandemia da Covid-
}

\author{
Title: Neoliberalism and crisis: the silent advance of surveillance capitalism in Brazilian \\ education during the Covid-19 pandemic
}

Leonardo Ribeiro da Cruz.

Universidade Federal do Pará

leocruz@ufpa.br

\author{
Jamila Rodrigues Venturini \\ Rede Latino Americana de Estudos sobre Privacidade, \\ Tecnologia e Sociedade (Lavits) \\ jamilarv@riseup.net
}

\begin{abstract}
Resumo
Atualmente, podemos observar o crescimento de acordos envolvendo instituições públicas de ensino e empresas cuja valorização advêm da coleta e tratamento de dados de seus usuários para a utilização de diversos tipos de aplicativos educacionais. Esse crescimento acelerou durante a pandemia de Covid-19, quando a emergência do distanciamento social fez crescer a demanda por ensino remoto em tais instituições. Contudo, a adesão a tais acordos é realizada de forma silenciosa a partir de interações diretas entre empresas e instituições públicas e sem um debate público sobre seus riscos e consequências para a educação pública brasileira, principalmente as que envolvem a segurança de dados e a terceirização de parte do gerenciamento de tecnologias de informação. Esse artigo tem como objetivo discutir a adoção de tecnologias educacionais de empresas cujo modelo de negócios é pautado pela coleta e tratamento de dados dos usuários, particularmente durante a pandemia da Covid-19 no Brasil. Veremos, por meio da análise dos dados disponíveis sobre sua atuação, que o avanço desse mercado sobre a educação pública do país, acelerado durante a crise de saúde, é sustentado pelo planejamento e execução de um projeto de ampliação do envolvimento de empresas privadas e de diminuição do investimento público no setor.

Palavras-Chave: Capitalismo de Vigilância; Tecnologias Educacionais; Educação Vigiada; Educação; Vigilância.
\end{abstract}

\begin{abstract}
Research has shown, a growing trend on the development of "partnerships" between Brazilian public educational institutions and global technology companies offering platforms for education based on the intense collection and processing of users data. These have accelerated during the Covid-19 pandemic due to the adoption of social isolation measures that imply the massive adoption of remote education. However, such public-private agreements are not followed by any transparency measure or public debate about their risks and consequences for Brazilian public education, especially regarding data privacy and security and the privatization of part of the operation of these institutions, compromising their technological autonomy. This article aims at documenting and questioning this process, particularly during the health crisis. It shows, through the analysis of the available data on its performance, that the advancement of this market on public education in the country, accelerated during the health crisis, is supported by the planning and execution of a project to expand the involvement of private companies and the decrease in public investment in the public educational sector.
\end{abstract}

Keywords: Surveillance capitalism; Educational Technologies; Surveilled Education; Education; Surveillance.

Cite as: Cruz, L. R. \& Venturini, J. R. (2020). Neoliberalism and crisis: the silent advance of surveillance capitalism in Brazilian education during the Covid-19 pandemic (Neoliberalismo e crise: o avanço silencioso do capitalismo de vigilância na educação brasileira durante a pandemia da Covid-19). Brazilian Journal of Computers in Education (Revista Brasileira de Informática na Educação - RBIE), 28, 1060-1085. DOI: 10.5753/RBIE.2020.28.0.1060 


\section{Introdução}

O aumento da demanda pelo ensino remoto emergencial, motivado pela pandemia da Covid-19 em 2020, acelerou a adoção de tecnologias digitais para a interação entre docentes e estudantes em isolamento social. Para além dos desafios relacionados às diversas brechas digitais que esse processo implicou, a educação remota expôs o despreparo das instituições públicas em dispor de infraestruturas adequadas para a interação a distância e abriu espaço para um aumento na adoção de soluções oferecidas por grandes empresas do capitalismo global. Com isso, abriu uma oportunidade para o desenvolvimento de novos acordos entre as instituições públicas de ensino e empresas como Google ou Microsoft para o uso de uma série de serviços adaptados para o contexto educativo, como e-mail, mensagem instantânea, áudio e videoconferências, organizadores de sala de aula, espaço de hospedagem de arquivos em nuvens, documentos compartilhados online, etc.

Tais acordos, agora estabelecidos às pressas, são um reflexo de um longo processo de desinvestimento na educação pública, que - principalmente no âmbito do ensino superior impacta diretamente na capacidade de gestão das suas áreas de infraestrutura de tecnologias de informação (TI) (Parra, Cruz, Amiel, Machado, 2018 e Cruz, Amiel, Saraiva, 2019). Suas consequências ainda são muito obscuras - como grande parte das operações desse modelo de negócios - e vão desde a falta de segurança sobre o uso de dados dos atores escolares ${ }^{1}$ até a coleta massiva de metadados sobre as práticas e desempenho dos estudantes, capaz de criar diagnósticos precisos não só sobre seus comportamentos, como sobre a educação pública por meio de um vigilantismo que facilita o ranqueamento e segregação social com impactos diretos no aprofundamento das desigualdades sociais.

Contudo, mesmo sem conhecer por inteiro os riscos envolvendo tais acordos, estamos cada vez mais transferindo nossas relações educacionais e de pesquisa, agora digitalizadas, para os data centers de grandes empresas do capitalismo digital. São alunos, alguns ainda menores de idade, professores, pesquisadores e funcionários das instituições públicas educacionais que são inseridos, muitas vezes de forma compulsória e com poucas discussões internas, nesse modelo privado de negócios sem compreender suas possíveis consequências. Isso porque, em um país que há alguns anos enfrenta uma crise política, econômica - e agora de saúde - como o Brasil, cuja situação de austeridade tem sido combatida com a diminuição do orçamento público, a adoção de plataformas privadas para o ensino tem sido encarada como única solução para uma situação de falta de investimento e de estrutura em relação à educação pública.

Esse artigo tem como objetivo discutir a adoção de tecnologias educacionais de empresas globais de tecnologias cujo modelo de negócio é pautado na coleta e tratamento de dados dos usuários, particularmente durante a pandemia da Covid-19 no Brasil. Veremos, por meio da análise dos dados disponíveis sobre sua atuação, que o avanço desse mercado sobre a educação pública do país, acelerado durante a crise de saúde, é sustentado pelo planejamento e execução de

1 Recentemente, a empresa Google vem enfrentando algumas batalhas jurídicas em relação à privacidade e segurança de dados de jovens e crianças em seus serviços. Para mais detalhes, ver:

"Two children sue Google for allegedly collecting students' biometric data", publicado dia 3 de abril de 2020 em https://www.cnet.com/news/two-children-sue-google-for-allegedly-collecting-students-biometric-data/

"U.S. state of Arizona files consumer fraud lawsuit against Google", publicado dia 27 de maio de 2020 em https://www.reuters.com/article/us-google-arizona-lawsuit-idUSKBN2333CP

"YouTube plans sweeping changes to kids videos after \$170M fine", publicado dia 04 de setembro de 2019 em https://www.cnet.com/news/youtube-170m-fine-kids-video-policy-changes-google-settle-ftcinvestigation/?ftag=COS-05-10aaa0b

"Microsoft, Google and Apple clouds banned in Germany's schools", publicado dia 17 de julho de 2019 em https://nakedsecurity.sophos.com/2019/07/17/germany-bans-schools-from-using-tech-giants-clouds/ 
um projeto de ampliação do envolvimento de empresas privadas e de diminuição do investimento público no setor.

Partimos explorando os conceitos de capitalismo de vigilância (Zuboff, 2019) e governamentalidade algorítmica (Rouvroi \& Berns, 2019) que ajudam a compreender a lógica de operação de grandes e pequenas empresas de tecnologia atuais e a delinear as preocupações com seu avanço sobre a educação pública. Em seguida, considerando que o estabelecimento dessas relações público-privadas tem ocorrido principalmente por meio de interações diretas entre empresas e secretarias de educação ou instituições de ensino, analisamos dados quantitativos inéditos do avanço de acordos entre secretarias de educação, institutos federais e universidades com empresas globais de tecnologia desde a interrupção das aulas presenciais a partir de março de 2020. Além disso, apresentamos dois breves estudos de caso realizados em universidades públicas - uma estadual e uma federal - que adotaram as soluções educacionais da Google antes da pandemia de modo a aprofundar numa análise dos processos por detrás desse movimento. Em seguida, exploramos o processo de adoção das plataformas Google na educação básica e o papel da atual crise de saúde em criar uma pressão nesse sentido, a partir da análise de alguns exemplos retirados de notícias na imprensa. Finalizamos com algumas considerações sobre a relação entre o avanço do capitalismo de vigilância nas instituições educativas e propostas e políticas de caráter neoliberal para o uso de tecnologias na educação, retomando o histórico dessas políticas no país.

\section{Explorando o conceito de capitalismo de vigilância e seus impactos no contexto brasileiro}

Para compreender os interesses das empresas globais de tecnologia cujas soluções se baseiam na coleta e tratamento intensivo de grandes quantidades de dados (big data) no âmbito educativo e as possíveis consequências de seus avanços sobre as instituições educativas brasileiras, utilizaremos o conceito de capitalismo de vigilância, criado pela economista e professora emérita de Harvard Shoshana Zuboff (2019).

\subsection{A mercantilização do comportamento humano no capitalismo de vigilância}

Segundo a Zuboff, o capitalismo de vigilância inaugura um novo tipo de mercado digital que se apoia na ubiquidade das relações mediadas por computadores através da internet e tem como matéria-prima a sociabilidade humana traduzida em dados de comportamento, capturada por meio de plataformas digitais, redes de serviço, dispositivos eletrônicos ou data centers. Quanto mais presentes as empresas do capitalismo de vigilância estiverem nas interações que realizamos cotidianamente, mais dados sobre nossa sociabilidade são coletados, analisados e compilados. Seu processo de produção passa pela coleta em massa de dados extraídos de transações mediadas por computador, de sensores e dispositivos conectados a objetos, corpos e lugares, adquiridos a partir de bancos de dados corporativos ou governamentais, gerados por meio de câmeras de vigilância públicas e privadas, assim como satélites e metadados de operações não mercantis desenvolvidas por indivíduos na rede "no desenrolar da vida prática" (Zuboff, 2018).

Para Zuboff (2019), todos esses dados constituem uma mais-valia comportamental (behavior surplus), cuja possibilidade de tradução para a produção de algum tipo de mercadoria comercializável é a base do processo produtivo do capitalismo de vigilância. São armazenados em bancos de dados que se atualizam constantemente, a cada nova interação e a cada novo dado obtido ou produzido. Essa grande e crescente quantidade de dados é analisada, compilada, segmentada e recombinada em uma infinidade de perfis com poder preditivo sobre nosso comportamento.

Para o usuário - seja individual ou corporativo, público ou privado -, a coleta de dados é justificada como necessária para a customização ou "personalização" de sua experiência - que 
também está na base da especulação do mercado de comportamentos futuros descrito por Zuboff (2019). A criação de perfis permite a produção e apresentação de um ambiente digital supostamente individualizado segundo uma "inteligência" e previsões algorítmicas cujas lógicas de operação são totalmente desconhecidas por seus alvos.

Assim, nos ambientes e serviços digitais criados pelas empresas que atuam no capitalismo de vigilância - mecanismos de busca, redes sociais, aplicativos de localização e GPS, serviços de compras online, serviços de e-mail, dispositivos de "casa inteligente", sistemas operacionais etc. - se produz uma realidade algorítmica para cada usuário através da seleção e organização das informações que supostamente condizem com o seu perfil de dados. Essa produção possibilita maximizar a previsibilidade das ações dos usuários através da seleção de opções que ele terá acesso, a depender do tipo de características selecionadas na perfilização (perfil de consumo, de gostos culturais, de ideologia política, de orientação sexual, de interesses a assuntos diversos etc).

Antoinette Rouvroy e Thomas Berns dissertam sobre a racionalidade dessa espécie de governo algorítmico em artigo intitulado "Governamentalidade algorítmica e perspectivas de emancipação: o díspar como condição de individuação pela relação?” (2019). O artigo nos alerta a respeito da construção de um novo regime de verdade sobre a realidade social, erigido através de sistemas automáticos de coleta e processamento de uma grande quantidade de dados, que se apoia em uma suposta objetividade algorítmica e na possibilidade de atomização e personalização dos perfis de dados, sem a intervenção direta de sujeitos, e que teria o objetivo de produzir uma governamentalidade emancipada de qualquer "norma" ou "média" previamente concebida. Por se tratar da coleta e análise de dados que exprimem a totalidade de relações em um certo ambiente, aparentemente permitem apreender a realidade social em si.

A governamentalidade algorítmica é, para os autores, o modo de atuação de um tipo de poder que monitora e determina o comportamento dos sujeitos através do automatismo e da pretensa objetividade dos algoritmos. De acordo com Rouvroy e Berns, esse tipo de atuação elimina o que é incalculável e apresenta somente os resultados de sua previsibilidade como horizonte de avaliação e de tomada de decisão para os sujeitos, impedindo uma série de outros desdobramentos. Esse modelo de exercício de poder pode ser facilmente encontrado nas relações entre empresas do capitalismo de vigilância e seus usuários, mas, como ele está presente de forma intrínseca em dispositivos que agora permeiam boa parte das nossas relações sociais, se impõe sobre outras formas de atuação, se apresentando como o modelo mais eficiente para gerenciar relações de poder dentro da sociedade ${ }^{2}$. Assim, ele se torna padrão de atuação nas relações de trabalho, nas relações familiares e, no caso dessa pesquisa, nas relações educacionais.

Esses "ativos de vigilância" (surveillance assets) (Zuboff, 2019) - que vão desde a propriedade sobre os algoritmos e ambientes digitais até a construção de grandes data centers se tornam rentáveis através criação de um mercado onde se possa comercializar os produtos de predição do comportamento dos usuários - a possibilidade de acessar, selecionar e modular as informações disponíveis nos ambientes digitais transitados por usuários associados a uma infinidade de perfis comportamentais. Os compradores dessas mercadorias são empresas ou indivíduos interessados na previsão e controle do comportamento dos usuários através da oferta

2 Embora seja observável a digitalização dos serviços de educação, cidadania e consumo, esse processo incide de forma desigual no Brasil em termos geográficos e sociais. Segundo a pesquisa “TIC Domicílios 2018”, produzida pelo Comitê Gestor da Internet no Brasil (CGI, 2019), a região Norte e Nordeste do país, por exemplo, possuem a menor proporção de domicílios com acesso à internet por Banda Larga Fixa (44\%). Tais números se explicam pelo valor do acesso à internet no país e pela falta de investimento para que a infraestrutura da internet alcance as localidades em áreas rurais e de difícil acesso. Assim, as desigualdades digitais acompanham as desigualdades sociais. Nessas localidades, a ampliação da digitalização de serviços implica no aumento das dificuldades das populações em acessar serviços públicos e implicam numa acentuação das desigualdades, como fez-se visível durante a crise de saúde causada pela pandemia do Covid-19 no país. 
ou ocultação de certos tipos de informações - sejam elas publicitárias, pessoais ou políticas. O controle do mercado se dá através do investimento na propriedade intelectual dos algoritmos, da invenção, inovação e comercialização de serviços digitais, na possibilidade de influenciar a produção de políticas regulatórias ${ }^{3}$ e na propriedade de data centers.

As operações técnicas e econômicas descritas por Zuboff são realizadas com o objetivo de transformar a experiência humana digitalizada em "matéria prima para práticas comerciais obscuras de extração, predição e venda" (Zuboff, 2019, p. 08). Quanto mais atividades cotidianas são realizadas através de suas estruturas, maior será seu poder de mercado.

A empresa Google - e sua holding de negócios Alphabet.Inc - é a grande pioneira desse modelo de negócios. Para Zuboff (2019), foi ela que conseguiu criar um modo de produzir mercadorias a partir das interações realizadas em suas plataformas, como seu mecanismo de busca. A Google criou também um mercado próprio, em que anunciantes e produtores de conteúdo ou serviços, incluindo ela própria, comercializam a sua mercadoria preditiva ${ }^{4}$. Contudo, atualmente, as cinco empresas com maior ganho no mercado de capitalização ${ }^{5}$ e presentes na lista de seis maiores empresas em valor de mercado do mundo ${ }^{6}$ - Apple, Microsoft, Alphabet (Google), Amazon e Facebook - têm como parte de seus ativos a coleta e tratamento de dados. As mercadorias produzidas por elas estão reestruturando mercados, processos produtivos, estratégias políticas, formas de trabalho, políticas públicas, etc.

\subsection{Aspectos colonialistas do capitalismo de vigilância}

Embora Shoshana Zuboff delineie de forma brilhante o funcionamento lógico de um mercado assente em mercadorias de vigilância, sua conceitualização foi acompanhada de algumas críticas que, ao nosso ver, devem ser levadas em consideração. Evgeny Morozov, em uma resenha crítica ao mais recente livro da autora, afirma que seu maior problema é não conseguir apresentar o que há de "capitalismo" no capitalismo de vigilância. Para ele, ela perdeu a oportunidade de avançar conceitualmente ao não aprofundar em sua relação com a lógica de desenvolvimento do capitalismo neoliberal, principalmente em sua atuação assimétrica em diferentes partes do globo. Morozov defende que há uma razão para acreditar que, da mesma forma que o capitalismo industrial tinha um padrão específico de exploração em determinados territórios e populações um para os centros de poder e consumo, outro para a periferia e a produção - o mesmo acontece com o capitalismo de vigilância (Morozov, 2019).

3 É interessante perceber que o aumento da importância e do poder econômico das grandes empresas do capitalismo de vigilância é acompanhado por um crescimento no seu poder político, formado e mantido, nos EUA, dentro dos moldes da política tradicional: na formação de lobby. Segundo os dados publicados pela organização não governamental CRP, Center for Responsive Politics - que tem como objetivo monitorar e quantificar a participação empresarial na formação de lobby e em apoios de campanhas nos EUA por meio do seu site opensecrets.org -, desde 2011, empresas como a Alphabet (Google), Amazon e Facebook figuram na lista dos maiores lobistas do país. Só em 2013, o Google gastou cerca de US\$15 milhões em lobby.

4 A empresa Google possui uma série de aplicativos que organizam uma grande parte do mercado de marketing na internet. Ela oferece serviços que colocam em contato os publishers, produtores de conteúdo que comercializam espaços de publicidade em seus sites (ou vídeos) e os anunciantes, que adquirem esses espaços a partir da perfilização de seus usuários. Ela oferece também espaços em seus próprios serviços, como nos mecanismos de busca ou nas sugestões de vídeos. Com esse mercado, a Google recebe um terço de todo o investimento em propaganda na internet e vem enfrentando diversas suspeitas de monopólio, nos EUA e na Europa. Ver mais em https://www.morningbrew.com/daily/stories/2020/07/23/googles-antitrust-issues-not-just-search

5 Ver: "Here are the companies that gained and lost in value in 2019" em https://www.forbes.com/sites/sergeiklebnikov/2019/12/20/here-are-the-companies-that-gained-and-lost-themost-market-value-in-2019/\#170c8efd299e

6 Ver "Top Companies in the World by market value" em https://www.statista.com/statistics/263264/topcompanies-in-the-world-by-market-value/ 
Rafael Evangelista, em uma resenha sobre o mesmo livro, chegou a conclusões parecidas. Segundo ele, falta ao conceito uma perspectiva que não universalize as relações ocorridas nas principais democracias liberais, mas que consiga compreender como esse novo modo de acumulação se insere nas assimetrias de poder globais, em especial as relacionadas à divisão internacional do trabalho, da riqueza e do conhecimento (Evangelista, 2019). Contudo, o autor não invalida a potencialidade do conceito. Pelo contrário, ele acha possível atualizá-lo a partir de novas perspectivas "que deem conta de descrever um funcionamento que evidencie a possível persistência e aprofundamento de assimetrias norte-sul” (Evangelista, 2017, p. 250).

Acreditamos na importância do delineamento do conceito por Zuboff para o entendimento da lógica do capitalismo de vigilância, seu modo de funcionamento e o crescimento do mercado de vigilância de dados. Contudo, o deslocamento citado por Evangelista faz-se necessário para a realização de uma análise do funcionamento desse mercado em lugares em que a desigualdade econômica e de poder impedem e se aprofundam na busca do suposto equilíbrio entre mercado, democracia, liberdade e atuação política - que, para Zuboff (2019) estaria abalado pelo surgimento de um novo modelo de acumulação.

Sendo o capitalismo de vigilância, como afirma Zuboff, um fenômeno estadunidense, o fluxo de capital, trabalho e conhecimento do capitalismo global faz com que a lógica desse mercado opere de forma muito desigual em países do Sul Global, como o Brasil. O fluxo de extração de dados, que são coletados aqui para se transformarem em lucro e investimento para as empresas do Vale do Silício, acaba por aprofundar as desigualdades do capitalismo liberal, colocando o país no papel subalterno em que sempre esteve. Portanto, devemos analisar a atuação do capitalismo de vigilância como dependente dos mesmos fluxos globais do capitalismo liberal, aprofundando relações pré-existentes de dependência econômica, tecnológica e de conhecimento e as relações de exploração de matéria-prima e de força de trabalho.

Em um mercado em que o retorno do investimento está diretamente relacionado com o poder algorítmico de predição e consequentemente ao acesso a cada vez maiores quantidades de dados, as empresas que operam na lógica do capitalismo de vigilância se encontram numa corrida constante por novos mercados para a exploração. A fala de Hal Varian, economista que ocupa o posto de Chief Economist na Google, recuperada por Zuboff (2018) é explícita nesse sentido: segundo ele, "qualquer coisa que aumente o uso da internet, em última instância, enriquece a Google" e "qualquer bit de dados, mesmo que aparentemente trivial, tem valor potencial", para a empresa.

Desse ponto de vista, os países do Sul Global e sua massa populacional desconectada são uma nova fronteira a ser explorada. No entanto, garantir o acesso igualitário a internet e a adesão voluntária a suas plataformas parece ser um desafio em economias marcadas por inúmeras desigualdades estruturais. A solução encontrada passa pelo uso de seu poder econômico e de negociação. $\mathrm{O}$ estabelecimento de acordos de diversos tipos com entes estatais que garantam o intercâmbio com bases de dados públicas pode ser um atalho, do mesmo modo que "parcerias" institucionais que obriguem a adesão de milhares de pessoas a seus sistemas ou plataformas.

Esse tipo de acordo público-privado se encontra na base dos processos de digitalização promovidos em resposta a pressões de organizações internacionais e, em muitos casos, com seu apoio financeiro. Sem contar com uma infraestrutura ou capacidades adequadas para o armazenamento e processamento das enormes quantidades de dados necessárias para uma suposta gestão mais eficiente ou "inteligente", governos e instituições públicas se veem forçados a recorrer às empresas de tecnologia globais. Além disso, frente aos crescentes questionamentos jurídicos à coleta excessiva de dados e ao avanço regulatório nesse mesmo nos Estados Unidos e Europa, a opção por mercados onde garantias e proteções são escassas se torna ainda mais atrativa reproduzindo e se somando ao antigo modelo colonial de exploração do capitalismo industrial. 


\section{Avanços e desafios metodológicos para analisar o avanço do capitalismo de vigilância na educação}

Podemos observar a dimensão do avanço desse mercado sobre a educação pública brasileira através dos dados do projeto Educação Vigiada $^{7}$. O projeto é uma cooperação entre acadêmicos e atores da sociedade civil organizada para coletar, divulgar e discutir dados e informações sobre os acordos realizados entre instituições públicas de ensino e empresas do capitalismo de vigilância no Brasil.

Cabe ressaltar que informações sobre a atuação das empresas envolvidas no mercado de dados no âmbito educativo não são fáceis de conseguir, uma vez que, em muitos casos, se trata de acordos bilaterais realizados diretamente entre empresas e instituições públicas. Em um país como o Brasil, isso significa que não há uma fonte oficial de informação centralizada sobre a adoção dessas plataformas.

Por outro lado, tampouco as empresas envolvidas oferecem informações públicas sobre as parcerias que realizam. Mesmo as informações disponíveis nos contratos de adesão estabelecidos por essas empresas - os chamados Termos de Uso e suas Políticas de Privacidade - são em geral ambíguos, confusos e imprecisos (Venturini et al., 2019) ${ }^{8}$. Além disso, seus algoritmos de coleta e tratamento de dados são protegidos por leis de propriedade intelectual, o que impede sua auditoria e a validação das escassas informações oferecidas em contrato sobre as condições do tratamento desses dados. De acordo com Zuboff (2018), a ocultação de informações sobre a sua atuação faz parte do modelo de negócio do capitalismo de vigilância. Seu próprio funcionamento está ancorado em uma relação desequilibrada entre privacidade e transparência. A utilização de seus serviços está condicionada à aceitação de Termos de Uso que privilegiam a coleta de dados dos usuários ao mesmo tempo em que torna incógnita as operações realizadas com esses dados. Esse desequilíbrio se materializa no controle de um mercado de difícil regulação. Assim, “[o] capitalismo de vigilância prospera na ignorância do público" (Zuboff, 2018, p. 50).

A ausência de informação sobre os acordos estabelecidos no âmbito educativo se soma à estratégia de invisibilização de sua operação para o público e de silenciamento de qualquer debate aberto sobre suas potenciais consequências. Nesse sentido, a escassez de dados sobre a atuação desse mercado afeta também a produção de conhecimento sobre ele. Para isso se faz necessário desenvolver metodologias como a análise de eventuais publicações nos Diários Oficiais, pedidos de informação diretos a instituições educativas previamente identificadas, a análise de fluxos de dados entre servidores institucionais e privados, entre outras que combinem diferentes metodologias para tentar chegar a um cenário do que ocorre em âmbito nacional. A autonomia de estados e municípios em desenvolver esse tipo de acordo e a ausência de políticas públicas que regulem esse tipo de contratação torna um mapeamento exaustivo a nível nacional ainda mais complexo.

Buscando avançar nesse diagnóstico, o projeto Educação Vigiada, com apoio da Fundação Derechos Digitales, desenvolveu uma metodologia híbrida baseada principalmente no uso de um software escrito em linguagem Python e executado em um terminal de comando de um sistema operacional Gnu/Linux ${ }^{9}$ para mapear em quais data centers estão alocados os e-mails de uma lista de domínios (como @ufpa.br). Deste modo, conseguiu identificar se os e-mails institucionais das

7 https://educacaovigiada.org.br

8 Especificamente sobre plataformas educativas ver o relatório "Educação, Dados e Plataformas", organizado pela Iniciativa Educação Aberta, com apoio do Instituto Alana. Disponível em: https://aberta.org.br/educacao-dadose-plataformas/.

9 O software e as listas utilizadas estão disponíveis em licença livre em https://gitlab.com/ccsl-ufpa/get-mxuniversities/ 
universidades públicas, institutos federais e secretarias estaduais de educação estavam armazenados em servidores próprios ou privados e, nesse caso, de quais empresas.

Os acordos aqui analisados tratam da utilização, por instituições públicas de ensino, de uma suíte de softwares educacionais desenvolvida pela Google (Google Suite for Education) ou pela Microsoft (Office 365), que incluem agenda, ferramentas colaborativas de produção de texto, salas de aula virtuais, aplicativos de videoconferência, espaço de armazenamento de arquivos e ferramentas de comunicação, como aplicativos de mensagens e e-mails. Para o usuário ter acesso aos serviços, ele deve ter uma conta de e-mail da empresa registrada pela instituição de ensino um e-mail institucional criado nos servidores privados. Em grande parte dos casos, é utilizado o próprio domínio institucional, como @usp.br, @unicamp.br, @ufpa.br, que é direcionado automaticamente para os data centers das empresas. Em outros, cria-se um subdomínio próprio para alunos ou professores, como @ professor.utfpr.edu.br ou @ estudante.ufscar.br. Há ainda instituições de ensino que realizaram acordos tanto com a Google e quanto com a Microsoft e disponibilizam assim dois subdomínios de e-mail, como a Secretaria Estadual de Educação de São Paulo, que tem os subdomínios@educacao.sp.gov.br e @aluno.educacao.sp.gov.br hospedado em servidores da Microsoft e @al.educacao.sp.gov.br hospedado em servidores da Google. Contudo, a possibilidade de migração dos e-mails institucionais para data centers privados e externos à instituição oferece, às instituições de ensino, uma solução técnica para um problema que, como veremos, é recorrente na educação pública brasileira: a falta de investimento nas estruturas de tecnologias de informação.

O software funciona através da automatização do comando host, próprio de um pacote de softwares de análise de rede chamado bind-tools, disponível nos repositórios de programas das distribuições Gnu/Linux. Esse comando permite a identificação dos registros de "mail exchange" - ou registro MX - de um certo domínio de e-mail. Esses registros apontam o direcionamento realizado pelo domínio aos servidores onde eles estão armazenados. Por exemplo, o comando host ufpa.br aponta para os seguintes registros de $\mathrm{mx}$ :

ufpa.br mail is handled by 5 ALT2.ASPMX.L.GOOGLE.COM

ufpa.br mail is handled by 5 ALT1.ASPMX.L.GOOGLE.COM.

Código 1: resultado do comando host ufpa.br

Isso significa que os e-mails do domínio @ufpa.br são direcionados para servidores da empresa Google. Servidores da Microsoft apontam para mail.protection.outlook.com. No caso das instituições que mantém soluções próprias, o comando host apresenta os seguintes resultados:

ufba.br mail is handled by $5 \mathrm{mx}$.ufba.br

Código 2: resultado do comando host ufba.br

O programa executa o comando a partir de uma lista predeterminada de domínios de e-mail, elaborada manualmente a partir de buscas nos websites das instituições. Visto que alguns acordos preveem a criação de novos domínios, como nos casos de endereços específicos para professores e estudantes, a busca manual deve ser realizada periodicamente e a lista de domínios pesquisados aumenta.

Ao descobrir para onde os domínios de e-mail listados são direcionados, o software nos permite, portanto, saber onde os e-mails institucionais estão armazenados. A indicação de um registro da Google ou da Microsoft aponta para a possibilidade de que a instituição realizou acordos para a utilização da suíte de softwares desta ou daquela empresa. Para que essa 
possibilidade possa ser verificada, os dados são confirmados através de consultas diretas às instituições que apresentem relações com empresas privadas por meio de requisições de informação baseadas na Lei de Acesso à Informação (Lei n. 12.527/2011). A confirmação nos indica que o direcionamento dos e-mails institucionais para servidores privados faz parte de acordos firmados entre a instituição e as empresas. Os resultados são atualizados mensalmente e atualizados no website https://educacaovigiada.org.br.

Foi só a partir do desenvolvimento de uma ferramenta própria que foi possível coletar dados de pesquisa sobre a atuação das empresas do capitalismo de vigilância sobre a educação pública brasileira. Através dela, foi possível conhecer e divulgar a dimensão dessa atuação através de dados inéditos sobre a quantidade de acordos realizados. Os resultados atualizados em 01 de outubro de 2020 seguem abaixo.

\section{O avanço do capitalismo de vigilância nas instituições educativas brasileiras}

Os dados do projeto Educação Vigiada em outubro de 2020 indicavam que de 193 instituições analisadas, 145 (cerca de 74\%) têm seus e-mails institucionais alocados em data centers da Google ou da Microsoft, únicas grandes corporações de tecnologia globais identificadas atuando no mercado da educação pública brasileira pelo projeto. Dentre as instituições que possuem algum tipo de acordo com Google e Microsoft, 84\% são universidades estaduais, 65\% universidades federais, $78 \%$ institutos federais de educação e 76\% secretarias estaduais de educação.

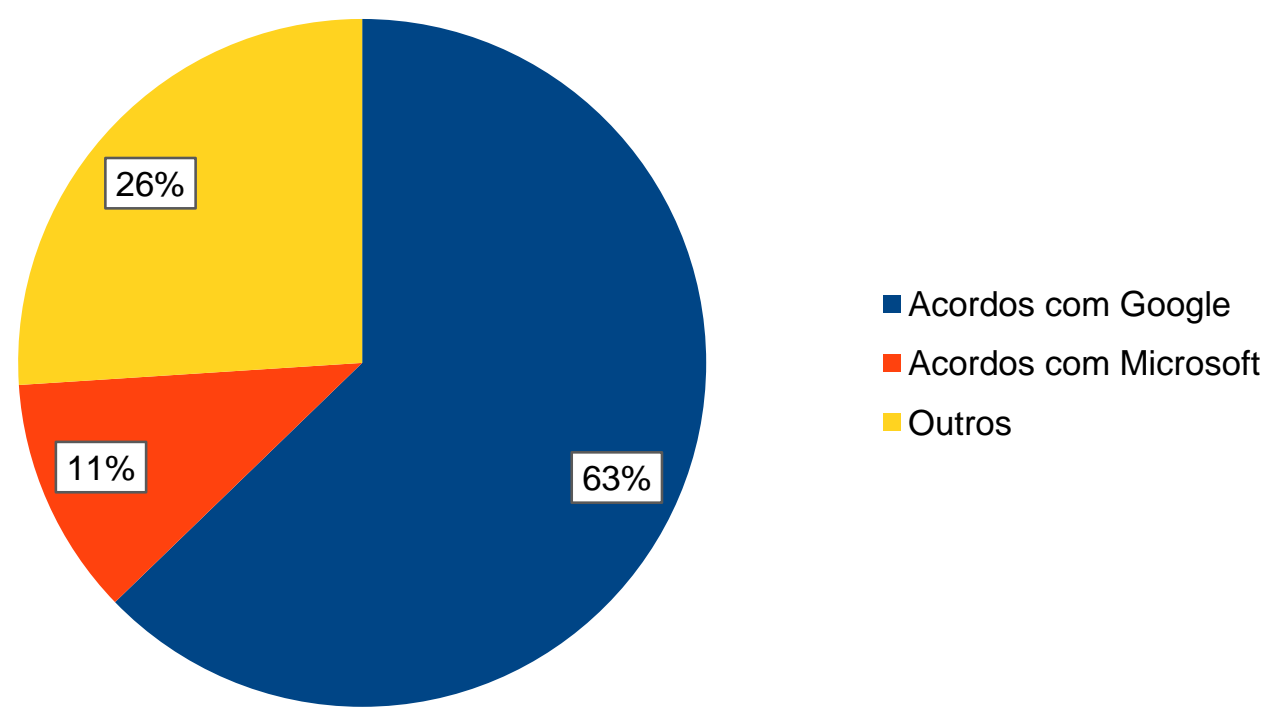

Figura 1: Instituições Públicas de Ensino por local de armazenamento de e-mails. Fonte: educacaovigiada.org.br

A empresa Google é quem detém o maior controle sobre esse mercado, como mostrado na Figura 1. Ela armazena dados de $63 \%$ das instituições públicas de ensino e é responsável por cerca de $85 \%$ dos acordos realizados. 


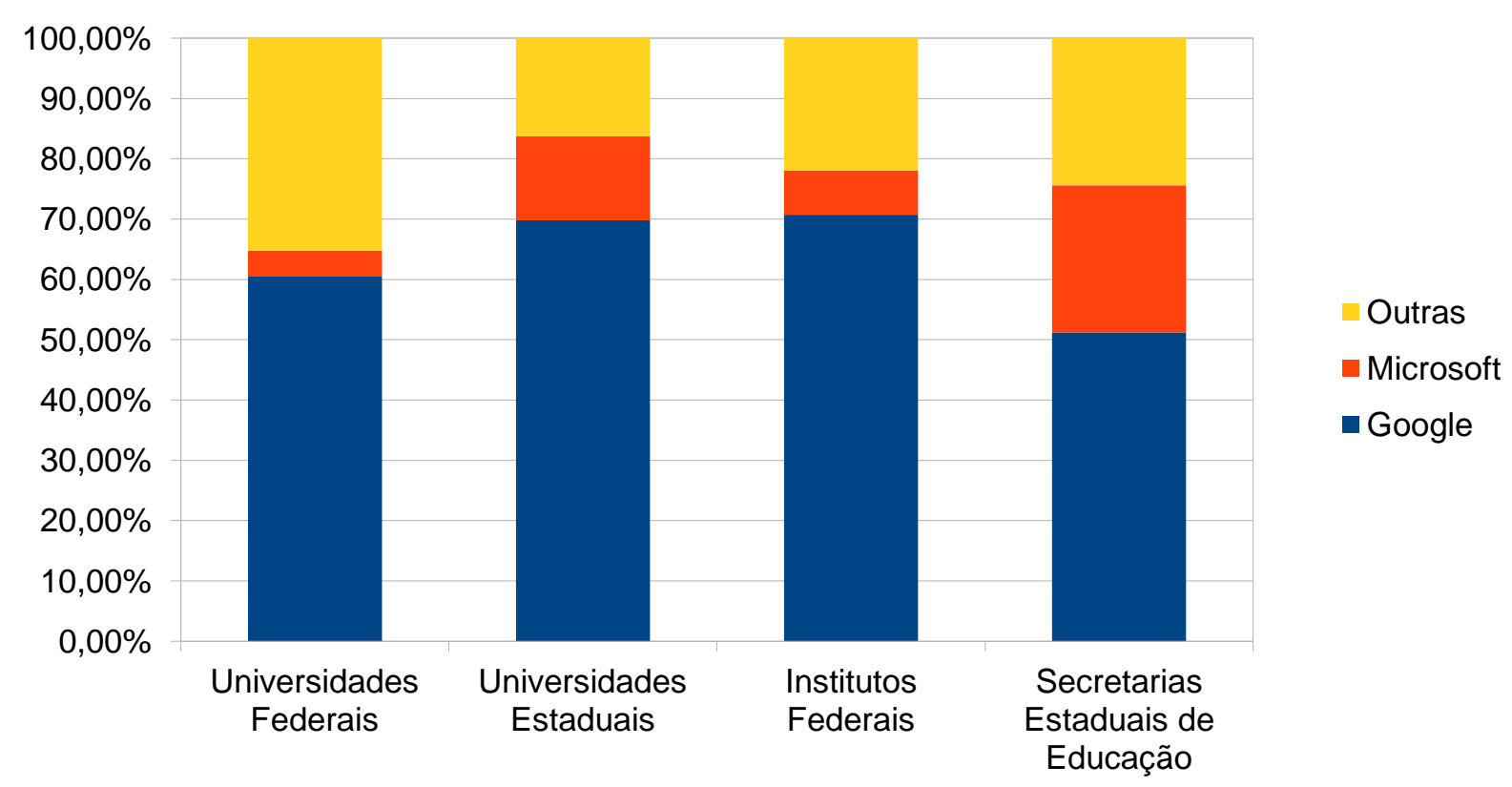

Figura 2: Direcionamento dos servidores de e-mail das Instituições Públicas de ensino.

Com os dados históricos, é possível perceber o crescimento da demanda por estrutura tecnológica privada a partir da emergência da pandemia de Covid-19, em especial nas universidades federais. Em março de 2020, o total de universidades federais que tinham e-mails institucionais alocados em servidores da Google era de $42 \%$, tendo chegado a $61 \%$ em outubro. Já o total de instituições com e-mails hospedados na Google ou Microsoft, nesse caso considerando toda a amostra, subiu de $63 \%$ em março de 2020 para $74 \%$ em outubro.

A partir desses dados, pela primeira vez conseguimos dimensionar empírica e quantitativamente o avanço de grandes empresas do capitalismo de vigilância sobre a educação pública brasileira em um curto período de tempo. O cenário aponta para o crescimento de um mercado amplo, acelerado e fortemente centralizado em duas grandes corporações que contam com capacidades de armazenamento e processamento que nenhuma instituição pública de ensino seria capaz de manter localmente, profissionais dedicados ao redor do mundo e em uma rede de empresas locais parceiras que auxiliam nos acordos de adesão e na migração das informações.

Contudo, embora nos permitam ter uma dimensão do problema, os dados pouco dizem sobre a forma de atuação desse mercado e o que explica seu crescimento. Esse crescimento não pode ser explicado sem uma análise das políticas de investimento na educação pública. Seguindo Maria Lindh e Jan Nolin, em artigo intitulado "Information We Collect: Surveillance and Privacy in the implementation of Google Apps for Education" "10 (2016), em que problematizam a implementação das ferramentas do Google para a educação nas escolas públicas da Suécia, a chave para compreender a facilidade com que as tecnologias educacionais baseadas no rastreamento $\mathrm{e}$ mineração dos dados consegue avançar nas instituições públicas de ensino deve ser a da estrutura político-econômica. Nesse sentido, a adoção das ferramentas educacionais da Google deve ser vista no contexto da evolução do envolvimento do mercado nas decisões envolvendo a reforma na educação pública.

10 Desde que foi criado, o pacote educacional da Google foi apresentado com diferentes nomes. O primeiro foi Google Apps for Education. A seguir, o nome foi trocado por Google Suite for Education. Atualmente, a Google apresenta o pacote educacional de forma modular. Portanto, decidimos usar um termo mais genérico, como "tecnologias educacionais da Google" 
É a partir dessa chave que buscamos compreender o avanço das empresas do capitalismo de vigilância na educação pública brasileira nos últimos anos. Seu crescimento estaria atrelado, entre outros fatores, à queda de investimento público nos setores de tecnologias de informação das instituições públicas de ensino. $\mathrm{O}$ crescimento exponencial de dados necessários ao funcionamento dessas instituições, a depreciação de seus equipamentos de armazenamento e a baixa regulação do mercado de dados do país fez com que o mercado privado de tecnologias educacionais pudesse ser explorado.

Para comprovar essa tese, apresentamos a seguir dois estudos de caso realizados na Universidade Estadual de Campinas (Unicamp) e na Universidade Federal do Pará (UFPA) por meio de entrevistas com os gestores dos centros de computação e análise documental sobre os acordos estabelecidos com a Google em 13 de maio de $2016^{11}$ e 23 de janeiro de $2020^{12}$. A aproximação desses casos permite ter uma dimensão da lógica de expansão do capitalismo de vigilância para além do contexto atual, uma vez que ela não se inicia com a Covid-19.

\subsection{Crise econômica e vigilância: os casos da Universidade de Campinas e da Universidade Federal do Pará}

A evolução dos dados qualitativos e quantitativos das adesões às soluções tecnológicas privadas nos últimos anos sugere que o avanço do capitalismo de vigilância sobre a educação pública - ao menos no ensino superior - se dá de forma proeminente em situações de austeridade econômica. A aprovação de políticas econômicas de redução de gastos sociais na educação, que se refletem diretamente nas áreas de gestão de TI das instituições públicas de ensino, acabam por favorecer o crescimento do mercado de tecnologias educacionais, aumentando assim o escopo das empresas que controlam esse mercado. Esse parece ser o caso da Unicamp.

A Universidade Estadual de Campinas aderiu ao pacote de tecnologias educacionais da Google em 2016 e, a partir desta data, seus aplicativos ficaram disponíveis para docentes, alunos e funcionários da instituição. Segundo comunicado da instituição, o objetivo do acordo foi disponibilizar, para a comunidade acadêmica, um novo recurso de apoio ao ensino - em especial o aplicativo Google Classroom. Na época, sua utilização era voluntária e cabia ao docente escolher o recurso mais adequado para sua aula. A voluntariedade acabou em 2018, quando todas as contas de e-mail institucionais foram migradas para os data centers da Google.

A decisão tomada pelo Conselho de Tecnologias de Informação e Comunicação da Unicamp ${ }^{13}$ foi justificada com base nas possibilidades de utilização de recursos "em nuvem" em que os arquivos são armazenados em servidores da Google e acessados através da internet - e a redução dos custos com armazenamento e gerenciamento de dados em servidores locais, o que liberaria recursos e tempo da instituição para serem investidos em outras atividades. O raciocínio baseado na necessidade de corte de gastos na área é amparado por uma observável desvalorização dos recursos destinados a atender demandas por atualizações, crescimento ou novas necessidades em tecnologias de informação e comunicação da Universidade. Ao analisarmos o orçamento anual da UNICAMP ${ }^{14}$ é possível observar como esses recursos, distribuídos por meio do Plano de

11 Ver "Unicamp firma acordo com a Google para uso de aplicativos para educação", disponível em https://www.ccuec.unicamp.br/ccuec/noticias/2016/05/13/unicamp-firma-acordo-com-google-para-uso-deaplicativos-para-educacao

12 Ver "UFPA disponibiliza adesão de contas institucionais para a plataforma G-Suite do Google" em https://portal.ufpa.br/index.php/ultimas-noticias2/11262-ufpa-disponibiliza-adesao-de-contas-institucionaispara-a-plataforma-g-suite-do-google

13 Disponível em http://cameraweb.ccuec.unicamp.br/watch_video.php?v=4811S591D18U e em Disponível em https://www.youtube.com/watch?v=0yrm1f1CZns

14 Disponível em www.aeplan.unicamp.br/proposta_orcamentaria/orcamento.php 
Atualização Tecnológica Continuada (PATC), sofreram com um drástico desinvestimento desde 2010, com uma queda 2017 (de $\mathrm{R} \$ 3.300 .000,00$ para $\mathrm{R} \$ 868,507,00$ ).

Os acordos e contratos estabelecidos pela Unicamp evidenciam como a diminuição do investimento público aumenta a necessidade de transformar serviços públicos em investimentos privados. Trata-se, de certa forma, de uma terceirização do serviço de gestão de tecnologias da informação.

A busca por solução para um problema orçamentário parece ser também a motivação para a migração no caso da UFPA, que realizou um acordo com a Google em 2019 e, em janeiro de 2020, passou a oferecer contas dos aplicativos e e-mails da Google para toda a comunidade acadêmica (ainda de forma voluntária e com opção de não migração para os professores).

Em entrevista realizada em abril de 2019, o diretor do Centro de Tecnologias de Informação (CTIC) da UFPA afirmou que a universidade tinha intenção de realizar tal acordo devido à crescente falta de investimento na atualização do parque tecnológico da universidade e na contratação de técnicos para a manutenção de seus data centers. Segundo ele, a situação dos data centers era precária, com risco de falta de funcionamento, e não havia alternativas que não a apresentada pela empresa. De acordo com o CTIC, conforme apresentação posterior em reuniões setoriais com os institutos, $95 \%$ dos servidores de e-mail da universidade estavam ocupados.

Novamente, a crise econômica utilizada para justificar a redução de investimentos na educação superior pública favoreceu a ascensão de um mercado altamente concentrado de tecnologias educacionais. Cabe ressaltar que entre 2016 a 2020 - datas do primeiro e do último caso estudado por essa pesquisa - o país passou por diversas políticas que resultaram no desinvestimento da educação pública, como a lei do teto de gastos sociais (Emenda Constitucional n. ${ }^{\circ}$ 95), aprovada em 2016, que impõe um limite no investimento do estado em gastos em 20 anos ${ }^{15}$; seguidos do contingenciamento no orçamento das universidades federais pelo Ministério da Educação ${ }^{16}$ do atual governo brasileiro; e o lançamento do programa Future-se ${ }^{17}$, também pelo Ministério da Educação e Cultura, que incentiva as universidades federais a realizar acordos com instituições privadas.

Outro fator que incidiu na adesão das universidades federais às soluções comerciais para a educação foi a derrubada do Decreto n. 8.135/2013. Segundo ele, as comunicações de dados da administração pública federal direta, autárquica e fundacional deveriam ser realizadas por redes de telecomunicações e serviços de tecnologia da informação fornecidos por órgãos ou entidades da administração pública federal, incluindo empresas públicas e sociedades de economia mista da União e suas subsidiárias. A promulgação desse decreto pela presidenta Dilma Rousseff buscou a defesa das comunicações e dos dados da administração pública federal após as denúncias de espionagem realizadas por Edward Snowden ${ }^{18}$ e afetou tanto serviços de correio eletrônico como

15 Ver: "Promulgada a emenda constitucional do teto de gastos" em https://www12.senado.leg.br/noticias/materias/2016/12/15/promulgada-emenda-constitucional-do-teto-degastos

16 Ver: "Mesmo encerrado, o bloqueio segue causando prejuízos milionários às universidades" em https://oglobo.globo.com/sociedade/mesmo-encerrado-bloqueio-segue-causando-prejuizos-milionarios-asuniversidades-24079946

17 Ver: "Perguntas e respostas do Future-se" em http://portal.mec.gov.br/busca-geral/12-noticias/acoes-programase-projetos-637152388/78351-perguntas-e-respostas-do-future-se-programa-de-autonomia-financeira-do-ensinosuperior

18 Os documentos secretos compartilhados por Edward Snowden sobre o programa de espionagem dos serviços de inteligência dos Estados Unidos da América e do Reino Unido nos alertou sobre o caráter político desse tipo de vigilância econômica exercida pelo marketing digital. Quando os dados captados pelas grandes empresas do mercado digital da atenção podem ser acessados por agentes políticos de segurança, forçando sua identificação e apresentando algoritmos eficientes de busca, a vigilância exercida pelo mercado toma uma forma de espionagem 
o processamento e armazenamento de dados. Com isso, se restringiu a adesão das universidades federais às soluções propostas por empresas como a Google e a Microsoft.

No entanto, o decreto foi revogado em dezembro de 2018 pelo então presidente interino Michel Temer. O novo Decreto n. 9.637/2018 não propõe orientações específicas sobre a conduta das instituições de ensino superior, mas explicitamente prega a "integração e cooperação entre o Poder Público, o setor empresarial, a sociedade e as instituições acadêmicas" (art. $3^{\circ}$, inciso XV). Ao remover a necessidade de manutenção de estruturas de armazenamento e processamento de dados em instituições públicas federais, permite-se que cada vez mais instituições federais de ensino insiram seus alunos, professores e pesquisadores, de forma compulsória, no modelo de negócio do capitalismo de vigilância.

\subsection{Crise de saúde como oportunidade: educação remota emergencial e novos acordos no âmbito da educação básica}

Se a crise econômica somada à desregulação foram fatores determinantes para o avanço do capitalismo de vigilância na educação superior, a crescente procura por soluções digitais para resolver problemas trazidos à educação pública pela necessária interrupção das aulas presenciais nas instituições de ensino básico, somada à incapacidade dos gestores de oferecer uma estrutura adequada para a promoção de aulas virtuais, fez com que a procura por acordos com empresas do capitalismo de vigilância se intensificasse. Como resultado, segundo dados do projeto Educação Vigiada, entre março e outubro de 2020, houve um aumento de $15 \%$ no número de acordos realizados por Universidades Federais, $6 \%$ nos Institutos Federais e 17\% nas Secretarias Estaduais de Educação, que representou um aumento de $11 \%$ do total de acordos realizados pelas instituições de ensino pesquisadas.

Ainda que não tenha sido a pandemia da Covid-19 que introduziu no âmbito da educação básica a demanda pelo uso das novas tecnologias, a crise mundial de saúde impôs uma nova pressão pela digitalização das atividades de ensino e aprendizagem, em consequência, acentuando muitos dos desafios preexistentes para tanto e abrindo novos espaços para o avanço de acordos com empresas globais interessadas no setor. Ainda que tal interesse não se origine durante a crise de saúde, as estratégias do setor se tornaram particularmente agressivas desde a interrupção das aulas causada pelo avanço do coronavírus, reproduzindo a tendência já observada de expansão do capitalismo de vigilância em contextos de crise - ao menos no âmbito educativo.

É importante reconhecer que o ensino remoto emergencial durante a pandemia de saúde traz uma série de desafios que se somam e aprofundam o cenário de precariedades apontado acima e favorecem a adesão às soluções comerciais oferecidas pelas empresas globais de tecnologia. $\mathrm{O}$ primeiro tem a ver com a necessidade de um sistema que permita a interação em tempo real de uma grande massa de docentes e estudantes. No caso da educação básica, dados da pesquisa TIC Educação 2019 (NIC.br, 2020) indicam que apenas 14\% das escolas públicas dispunham de um ambiente ou plataforma virtual de aprendizagem, enquanto na rede particular o índice era de $64 \%$.

O recurso é fundamental para facilitar a interação entre docentes e estudantes, o compartilhamento de conteúdos e o desenvolvimento de atividades. A falta de investimentos prévios nesse tipo de ferramenta explica a corrida dos gestores em estabelecer acordos com grandes fornecedores comerciais de soluções educativas, criando um ambiente ainda mais propício para o avanço do capitalismo de vigilância. Entre as opções mais adotadas pelas

política nunca antes conquistada por qualquer tipo de governo. Desta vez, é através da permissividade da vigilância ubíqua implementada por um modelo de negócio que possibilita a formação de um aparato de controle político. A estrutura de captação e processamento de informações já está pronta, atuando de forma eficiente e largamente estabelecida pelas empresas do mercado digital. Basta aos mecanismos de repressão política acessálas. 
secretarias estaduais de educação para a educação remota a partir de plataformas digitais ${ }^{19}$ estão o Google Sala de Aula, as soluções da Microsoft, além de opções desenvolvidas localmente que incorporam essas ferramentas - como no caso de Pernambuco e São Paulo, por exemplo. Em outros estados foram ofertadas opções diversas que podem ser adotadas pelas instituições educativas de acordo com seu contexto e demandas, como no Maranhão. Outras soluções para a distribuição de conteúdos foram desenvolvidas em parceria com entidades como o Instituto Natura e Instituto Telefônica Vivo, como no caso do Amapá. ${ }^{20}$

TABELA 3: Adoção de ferramentas educacionais da Google durante a pandemia da Covid-19 pelas Secretarias Estaduais de Educação ${ }^{21}$

\begin{tabular}{|c|c|c|c|c|c|}
\hline Estado & Nome & $\begin{array}{l}\text { Data da } \\
\text { parceria }\end{array}$ & $\begin{array}{l}\text { Instituições } \\
\text { envolvidas }\end{array}$ & Público atingido & Referências \\
\hline $\begin{array}{l}\text { Alagoas } \\
(\mathrm{AL})\end{array}$ & & Maio 2020 & GetEdu & $\begin{array}{l}\text { Criação de contas } \\
\text { de e-mail para } 180 \\
\text { mil professores e } \\
\text { estudantes }\end{array}$ & $\begin{array}{l}\text { http://www.consed.org.br/c } \\
\text { entral-de- } \\
\text { conteudos/parceria-entre-a- } \\
\text { seduc-e-google-cria-180- } \\
\text { mil-e-mails-para- } \\
\text { professores-e-alunos-da- } \\
\text { rede-estadual }\end{array}$ \\
\hline Bahia (BA) & & $\begin{array}{l}\text { Abril } 2020 \\
\text { (expansão de } \\
\text { uma parceria } \\
\text { pré-existente } \\
\text { desde 2017) }\end{array}$ & $\begin{array}{l}\text { Instituto } \\
\text { Paramitas }\end{array}$ & & $\begin{array}{l}\text { http://institucional.educaca } \\
\text { o.ba.gov.br/noticias/secreta } \\
\text { ria-da-educacao-do-estado- } \\
\text { e-google-dialogam-sobre- } \\
\text { o-uso-do-google-sala-de- } \\
\text { aula } \\
\text { http://www.consed.org.br/c } \\
\text { entral-de- } \\
\text { conteudos/secretaria-da- } \\
\text { educacao-da-bahia- } \\
\text { promove-formacao-para- } \\
\text { professores-em-parceria- } \\
\text { com-google-classroom }\end{array}$ \\
\hline $\begin{array}{l}\text { Brasília } \\
\text { (DF) }\end{array}$ & & Abril 2020 & $\begin{array}{l}\text { Ensinar } \\
\text { Tecnologia }\end{array}$ & & $\begin{array}{l}\frac{\text { https://www.agenciabrasili }}{\text { a.df.gov.br/2020/04/09/ens }} \\
\text { ino-mediado-pela-internet- } \\
\text { comeca-com-google-sala- } \\
\text { de-aula/ }\end{array}$ \\
\hline Ceará (CE) & & Abril de 2020 & & & $\begin{array}{l}\text { https://www.ceara.gov.br/2 } \\
\text { 020/04/02/parceria-entre- } \\
\text { seduc-e-google-permite- } \\
\text { acesso-de-estudantes-e- } \\
\text { professores-a-ferramentas- } \\
\text { educacionais-online/ }\end{array}$ \\
\hline
\end{tabular}

19 A maioria dos estados adotou soluções híbridas para responder às gritantes disparidades no acesso à internet. Elas incluem parcerias com redes de televisão locais ou nacionais e a distribuição de conteúdos físicos.

20 Ver "Plataformas educacionais auxiliam professores e estudantes durante o isolamento por conta do coronavirus" em <https://www.portal.ap.gov.br/noticia/2603/plataformas-educacionais-auxiliam-professores-e-estudantesdurante-o-isolamento-por-conta-do-coronavirus >. Acessado em 8 ago. 2020.

21 Inclui apenas estados onde foram encontradas referências de oferta institucional das ferramentas por parte das secretarias, inclusive em opções multiplataforma. Não considera situações em que as instituições ficaram livres para adotar as plataformas consideradas mais adequadas, como o caso do Maranhão. Ver <https://www.legisweb.com.br/legislacao/?id=392146>. Acessado em 8 ago. 2020. 


\begin{tabular}{|c|c|c|c|c|c|}
\hline & & & & & 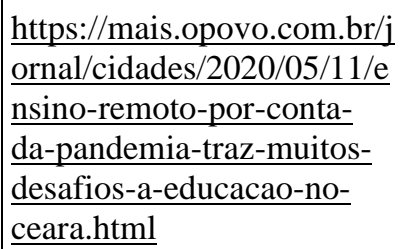 \\
\hline $\begin{array}{l}\text { Espírito } \\
\text { Santo (ES) }\end{array}$ & EscoLAR & $\begin{array}{l}\text { Abril de } 2020 \\
\text { (expansão de } \\
\text { uma parceria } \\
\text { pré-existente } \\
\text { desde 2019) }\end{array}$ & $\begin{array}{lr}\text { Instituto } & \text { de } \\
\text { Tecnologia } & \text { da } \\
\text { Informação } & \mathrm{e} \\
\text { Comunicação } & \\
\text { (Prodest), } & \\
\text { Governo } & \text { do } \\
\text { Maranhão } & \end{array}$ & & $\begin{array}{l}\text { https://sedudigital.edu.es.g } \\
\text { ov.br/google-for-education } \\
\text { https://sedu.es.gov.br/escol } \\
\text { ar/o-que-e-o-programa- } \\
\text { escolar }\end{array}$ \\
\hline $\begin{array}{l}\text { Mato Grosso } \\
\text { do Sul (MS) }\end{array}$ & & $\begin{array}{l}\text { Abril de } 2020 \\
\text { (expansão de } \\
\text { uma } \\
\text { experiência } \\
\text { piloto iniciada } \\
\text { no final de } \\
\text { 2019) }\end{array}$ & & $\begin{array}{l}\text { Criou contas de e- } \\
\text { mail para } 210 \text { mil } \\
\text { alunos e cerca de } 12 \\
\text { mil professores }\end{array}$ & $\begin{array}{l}\text { https://www.sed.ms.gov.br/ } \\
\text { sed-inicia-parceria-com- } \\
\text { google-e-leva-plataforma- } \\
\text { de-aulas-remotas-para- } \\
\text { toda-a-ree }\end{array}$ \\
\hline Paraíba (PB) & & Abril de 2020 & & & $\begin{array}{l}\text { https://paraiba.pb.gov.br/di } \\
\text { retas/secretaria-da- } \\
\text { educacao-e-da-ciencia-e- } \\
\text { tecnologia/noticias/secretar } \\
\text { ia-de-educacao-anuncia- } \\
\text { regime-especial-de-ensino- } \\
\text { da-rede-estadual-durante- } \\
\text { pandemia-do-novo- } \\
\text { coronavirus } \\
\text { https://sites.google.com/pr } \\
\text { od/see.pb.gov.br/pbeduca/p } \\
\% \text { C3\%A1gina- } \\
\text { inicial/forma\%C3\%A7\%C } \\
\text { 3\%A3o-remota/google- } \\
\text { class-room }\end{array}$ \\
\hline Paraná (PR) & Aula Paraná & Abril de 2020 & & $\begin{array}{l}592 \text { mil alunos e } 41 \\
\text { mil professores }\end{array}$ & $\begin{array}{l}\text { http://www.educacao.pr.go } \\
\text { v.br/servicos/Educacao/Ens } \\
\text { ino-Fundamental/Acessar- } \\
\text { o-Aula-Parana- } \\
\text { JVN6RYNP } \\
\text { https://www.gazetadopovo. } \\
\text { com.br/parana/aulas- } \\
\text { quspensas-covid-parana- } \\
\text { quatro-meses/ } \\
\text { https://www.bandab.com.b } \\
\text { r/cidades/secretaria- } \\
\text { ponitora-acesso-ao-aula- } \\
\text { ao-programa-e-diz-que-adesao- } \\
\text { todas-as-semanas/ }\end{array}$ \\
\hline $\begin{array}{l}\text { Pernambuco } \\
(\mathrm{PE})\end{array}$ & EducaPE & $\begin{array}{l}\text { Abril } 2020 \\
\text { (estado } \\
\text { desenvolve }\end{array}$ & & & $\begin{array}{l}\text { https://educape.educacao.p } \\
\text { e.gov.br/ }\end{array}$ \\
\hline
\end{tabular}




\begin{tabular}{|c|c|c|c|}
\hline & $\begin{array}{l}\text { parcerias com a } \\
\text { empresa na área } \\
\text { de educação } \\
\text { desde 2015) }\end{array}$ & & \\
\hline $\begin{array}{l}\text { Rondônia } \\
\text { (RO) }\end{array}$ & $\begin{array}{l}\text { Abril de } 2020 \\
\text { (não foram } \\
\text { encontradas } \\
\text { informações } \\
\text { sobre o } \\
\text { estabelecimento } \\
\text { da parceria para } \\
\text { o uso, porém há } \\
\text { registros de } \\
\text { formações } \\
\text { pontuais nessas } \\
\text { ferramentas em } \\
\text { 2019 e 2018) }\end{array}$ & & $\begin{array}{l}\text { http://www.rondonia.ro.go } \\
\text { v.br/alunos-da-rede- } \\
\text { publica-estadual-contam- } \\
\text { com-aulas-on-line-para- } \\
\text { manter-rotina-de-estudos- } \\
\text { em-rondonia/ } \\
\text { http://www.rondonia.ro.go } \\
\text { v.br/com-uso-de- } \\
\text { aplicativos-inteligentes- } \\
\text { governo-investe-na- } \\
\text { qualidade-da-educacao-no- } \\
\text { sul-de-rondonia/ } \\
\text { http://www.rondonia.ro.go } \\
\text { v.br/profissionais-da- } \\
\text { educacao-em-rondonia- } \\
\text { recebem-formacao-para- } \\
\text { trabalhar-com-aplicativos- } \\
\text { da-google-como- } \\
\text { ferramentas-educacionais/ }\end{array}$ \\
\hline $\begin{array}{l}\text { Rio Grande } \\
\text { do Norte } \\
(\mathrm{RN})\end{array}$ & $\begin{array}{l}\text { Maio de } 2020 \\
\text { (parceria em } \\
\text { negociação) }\end{array}$ & & $\begin{array}{l}\text { https://www.bandab.com.b } \\
\text { r/cidades/secretaria- } \\
\text { monitora-acesso-ao-aula- } \\
\text { parana-e-diz-que-adesao- } \\
\text { ao-programa-tem-subido- } \\
\text { todas-as-semanas/ } \\
\text { http://www.seec.rn.gov.br/ } \\
\text { Conteudo.asp?TRAN=ITE } \\
\text { M\&TARG=228165\&ACT } \\
=\& P A G E=\& P A R M=\& L B \\
\text { L=NOT\%CDCIA }\end{array}$ \\
\hline $\begin{array}{l}\text { Rio Grande } \\
\text { do Sul (RS) }\end{array}$ & Junho de 2020 & $\begin{array}{l}\text { Mais de } 800 \mathrm{mil} \\
\text { alunos e } 60 \mathrm{mil} \\
\text { professores }\end{array}$ & $\begin{array}{l}\text { https://escola.rs.gov.br/aula } \\
\text { s-remotas-o-que-e } \\
\text { https://educacao.rs.gov.br/a } \\
\text { ulas-nas-redes-publica-e- } \\
\text { privada-serao-retomadas- } \\
\text { em-modelo-de-ensino- } \\
\text { remoto-a-partir-de-1-de- } \\
\text { junho }\end{array}$ \\
\hline $\begin{array}{l}\text { Rio de } \\
\text { Janeiro }(\mathrm{RJ})\end{array}$ & Março de 2020 & & 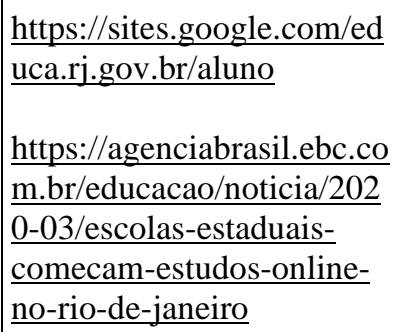 \\
\hline $\begin{array}{l}\text { Santa } \\
\text { Catarina } \\
(\mathrm{SC})\end{array}$ & $\begin{array}{l}\text { Abril de } 2020 \\
\text { (expansão de } \\
\text { uma } \\
\text { experiência }\end{array}$ & & $\begin{array}{l}\text { http://www.sed.sc.gov.br/p } \\
\text { rogramas-e- } \\
\text { projetos/16985-google-for- } \\
\text { education }\end{array}$ \\
\hline
\end{tabular}




\begin{tabular}{|c|c|c|c|}
\hline & & $\begin{array}{l}\text { piloto iniciada } \\
\text { no final de } \\
2019 \text { ) }\end{array}$ & $\begin{array}{l}\text { https://www.sc.gov.br/noti } \\
\text { cias/temas/coronavirus/cor } \\
\text { onavirus-em-sc-secretaria- } \\
\text { da-educacao-disponibiliza- } \\
\text { acesso-a-ferramenta-para- } \\
\text { atividades-nao-presenciais- } \\
\text { a-alunos-e-professores }\end{array}$ \\
\hline $\begin{array}{l}\text { São Paulo } \\
\text { (SP) }\end{array}$ & $\begin{array}{l}\text { Centro de } \\
\text { Mídia de SP }\end{array}$ & $\begin{array}{l}\text { Abril } 2020 \\
\text { (plataforma } \\
\text { incorpora } \\
\text { Google Sala de } \\
\text { Aula a partir de } \\
\text { parceria prévia } \\
\text { do governo do } \\
\text { estado com a } \\
\text { empresa) }\end{array}$ & $\begin{array}{l}\text { https://www.educacao.sp.g } \\
\text { ov.br/noticias/professor- } \\
\text { aprenda-ativar-suas- } \\
\text { turmas-no-google- } \\
\underline{\text { classroom/ }} \\
\text { https://www.saopaulo.sp.g } \\
\text { ov.br/ultimas- } \\
\text { noticias/educacao-de-sp- } \\
\text { disponibiliza-ferramentas- } \\
\text { online-gratuitamente-para- } \\
\text { toda-a-rede/ }\end{array}$ \\
\hline Sergipe (SE) & & $\begin{array}{l}\text { Julho de } 2020 \\
\text { (expansão de } \\
\text { uma } \\
\text { experiência } \\
\text { piloto iniciada } \\
\text { no final de } \\
\text { 2019) }\end{array}$ & $\begin{array}{l}\text { https://ajunews.com.br/cor } \\
\text { onavirus/ead-na-rede- } \\
\text { estadual-de-ensino-de- } \\
\text { sergipe-utilizara-a- } \\
\text { plataforma-google-for- } \\
\text { education/ } \\
\\
\\
\text { https://www.se.gov.br/noti } \\
\text { cias/Educa\%CC3\%A7\%C3 } \\
\% \text { A3o,\%20Cultura\%20e\% } \\
\text { 20Esportes/governo_de_se } \\
\text { rgipe_e_unit_possibilitam_- } \\
\text { uso_da_plataforma_google } \\
\text { _for_education_em_escola } \\
\text { s_estaduais }\end{array}$ \\
\hline
\end{tabular}

O segundo desafio tem a ver com a demanda de uma infraestrutura robusta, capaz de dar conta de comunicar milhares de estudantes ao mesmo tempo, e de plataformas flexíveis o suficiente para se adaptar aos mais variados tipos de dispositivos. Cabe observar que o acesso a computadores segue limitado no país e em vem decaindo nos últimos anos no país. Ao mesmo tempo, aumenta o número de pessoas que acessa a rede apenas pelo celular, especialmente entre as classes mais baixas. Nesse contexto, as soluções comerciais desenvolvidas com foco em dispositivos móveis aparecem como as melhores opções.

Outro desafio seria capacitar as professoras e professores para a utilização da ferramenta adotada para o ensino remoto, uma vez que as políticas de formação docente para o uso pedagógico das tecnologias anteriores à pandemia já se mostravam precárias. Cabe ressaltar que em 2019 apenas $25 \%$ das escolas possuíam um projeto de capacitação docente e $53 \%$ das escolas (58\% entre as públicas) não tinham em seu quadro nenhuma professora ou professor que tivesse recebido formação para o uso de computador e internet em atividades de ensino e aprendizagem (NIC.br, 2020). A maioria das docentes afirma aprender e se atualizar sobre o uso do computador e da internet por meio de contatos informais ou sozinha (NIC.br, 2020).

Nesse contexto, uma das justificativas para o uso de ferramentas privadas é de que elas são mais familiares para a comunidade educativa. No caso do governo do Distrito Federal, por 
exemplo, "a Secretaria de Educação optou pela Google para o Ensino Médio e Anos Finais depois de concluir que esta é a plataforma com melhor aderência", uma vez que a plataforma já estaria disponível na maioria dos telefones celulares utilizados por estudantes e professores da rede. ${ }^{22}$

Já no Espírito Santo, por exemplo, que aderiu não só ao pacote educativo do Google, como adquiriu equipamentos da empresa já em 2019, a opção teria advindo de uma pesquisa que identificava que as ferramentas Google já eram utilizadas em sala de aula. ${ }^{23} \mathrm{O}$ estado renovou e expandiu a parceria com a empresa para incorporar o Google Sala de Aula em uma plataforma desenvolvida pelo Instituto de Tecnologia da Informação e Comunicação (Prodest) para distribuir conteúdos educativos. ${ }^{24}$

De fato, na ausência de ações específicas que promovam a adoção de ferramentas alternativas desenvolvidas a partir de software livre ou de modelos de negócios menos invasivos do que os do capitalismo de vigilância, pesquisas indicam grande adesão das professoras e professores às soluções comerciais para atividades pedagógicas (NIC.br, 2020).

Se a possibilidade escolher as plataformas que mais se adéquem às suas demandas não constitui um problema em si, ${ }^{25}$ a construção de políticas públicas a partir de lógicas de consumo individuais parece ser extremamente problemática ao menos por duas razões. Por um lado, há uma desigualdade no acesso a informações sobre as implicações de cada uma dessas opções, inclusive do ponto de vista individual, em termos de privacidade, proteção de dados e de futuros usos discriminatórios dos dados coletados (Madden et al., 2017). A segunda é que dada a concentração das empresas globais de tecnologia, a ideia de livre escolha é bastante questionável.

Enquanto os discursos que sustentaram as primeiras políticas de uso das tecnologias digitais na educação estão associados a uma forte proposta pedagógica, ênfase na formação docente e desenvolvimento nacional, nos anos recentes eles parecem evoluir para uma concepção de que a conectividade e as tecnologias por si mesmas acelerariam a transformação das práticas escolares. A partir de uma associação direta entre tecnologias e melhoria educativa, tem-se uma naturalização acrítica de que qualquer solução - independente de seu desenho - poderia cumprir esse papel.

Esse movimento relativiza a importância de se desenvolver soluções que possam se adaptar às necessidades da realidade nacional, às demandas pedagógicas e curriculares do país e aos diferentes contextos educativos locais. A "personalização" oferecida pelas plataformas comerciais - que está na base do capitalismo de vigilância -, seria seu substituto. A introdução acrítica de tecnologias no espaço escolar sob um discurso de neutralidade também atua como um elemento de privatização e, consequentemente, de estímulo e criação de um mercado para uma série de empresas. $\mathrm{O}$ investimento para o desenvolvimento se redireciona para a compra.

22 Ver "Ensino mediado pela internet começa com Google na Sala de Aula" em <https://www.agenciabrasilia.df.gov.br/2020/04/09/ensino-mediado-pela-internet-comeca-com-google-sala-deaula/>. Acessado em 8 ago. 2020.

23 Ver "Ações Inovadoras garantem destaque da Educação Capixaba no Google" em <https://sedu.es.gov.br/Not\%C3\%Adcia/acoes-inovadoras-garantem-destaque-da-educacao-capixaba-nogoogle>. Acessado em 8 ago. 2020.

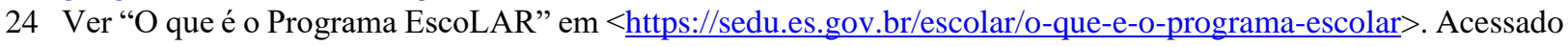
em 8 ago. 2020.

25 Entendemos neste estudo que as tecnologias não carregam um sentido ou função intrínseca e previamente definida na sociedade. Ao contrário, elas podem ser atribuídas de sentido de acordo com uma conjunção de fatores em cada período histórico e contexto específico. Sendo assim, a opção de um docente ou escola por uma determinada solução não é em si positiva ou negativa do ponto de vista educativo. No entanto, essas decisões devem ser analisadas tomando em consideração a influência da indústria de tecnologias e sua relação com estratégias econômicas e modelos de negócios externos ao ambiente educacional. Nos afastamos de concepções deterministas que entendem o computador como panaceia (Burbules \& Calister, 2000) e as tecnologias como artefatos neutros, ressaltando justamente seu caráter político que se reflete inclusive no seu desenho. 
Um estudo de campo realizado com diferentes produtores de conteúdos educativos brasileiros - de editoras tradicionais a start-ups ou grandes empresas de tecnologias - identificam o Estado como potencial grande comprador e docentes e estudantes como consumidores capazes de estimular a adoção de suas soluções. De acordo com Venturini (2014, p. 33),

[t]alvez, por influência da política de compra governamental de materiais didáticos, $o$ poder público é visto como o comprador ideal para os produtos. Por vezes, esse discurso não aparece de forma explícita, mas oculto num ideal de educação e escola que condiz com a implementação de inovações que beneficiaria certos tipos de negócios."

Se por um lado a transição em um contexto de urgência traz evidentes desafios no contexto da educação básica, cabe ressaltar que ela decorre de uma escolha, em alguns estados, pela manutenção do calendário escolar a qualquer custo em uma situação em que estudantes e professoras se viram enfrentadas a diversas dificuldades adicionais trazidas pela pandemia. A estratégia casa bem com as soluções criadas para a vigilância e que permitem o controle da assistência de professores e estudantes às aulas remotas.

Como explica o secretário estadual de educação do Paraná, “[o] monitoramento é relativamente fácil. A nossa estratégia é feita em cima do Google. São postadas dez tarefas de casa por dia na plataforma. $\mathrm{O}$ aluno responde e envia. $\mathrm{O}$ próprio sistema informa se o estudante acertou as questões ou não e, com a entrega dos conteúdos, registra a presença do aluno na aula. Esses dados são disponibilizados aos professores, diretores de escolas e núcleos regionais de ensino". ${ }^{26} \mathrm{O}$ estado também contratou um sistema de inteligência empresarial para analisar a adesão às aulas capaz também de monitorar a participação docente. ${ }^{27}$

\section{Neoliberalismo, educação e tecnologias}

Para além das situações de crise, a facilidade de adesão das instituições educativas a soluções tecnológicas privadas responde a uma série de fatores, inclusive à permeabilidade de empresas de tecnologia no setor educativo nas últimas décadas. Antes da abertura comercial da internet e do surgimento do capitalismo de vigilância enquanto modo de operação, as relações entre o mercado de tecnologias e a educação pública no Brasil já estavam articuladas. Nesse sentido, nos parece relevante recuperar o histórico de políticas públicas destinadas a promover o uso educativo das tecnologias de informação e comunicação na educação básica e como ganha influência um discurso que favorece a lógica da governamentalidade algorítmica desde o início do século.

\subsection{Uma nova pauta de reformas}

As reformas educativas de cunho neoliberal ocorridas nos anos 90 se centraram em questões de organização e gestão dos sistemas educacionais - buscando torná-los mais eficientes e suas instituições mais autônomas em relação ao controle central -, e na implementação de mecanismos de avaliação que visavam certificar a qualidade do ensino. As políticas de descentralização da gestão educativa respondiam a uma demanda por redução do aparato estatal e restrição orçamentária e ao mesmo tempo, argumentava-se, buscavam aproximar os conteúdos escolares

26 Ver "Ensino remoto no Paraná: governo fala em sucesso; professores questionam qualidade da aprendizagem dos alunos" em <https://www.apufsc.org.br/2020/07/08/ensino-remoto-no-parana-governo-fala-em-sucessoprofessores-questionam-qualidade-da-aprendizagem-dos-alunos/>. Acessado em 8 ago. 2020.

27 Ver "Rede pública vai para $4^{\circ}$ mês de ensino a distância. Como funciona o Aula Paraná?" em $<$ https://www.gazetadopovo.com.br/parana/aulas-suspensas-covid-parana-quatro-meses/>. Acessado em 8 ago. 2020 . 
das culturas locais desde uma lógica do consumo, o que inclui no interior da escola uma tensão entre um projeto de igualdade e a demanda por personalização. Como aponta Dussel (2018),

Se bem as relações entre cidadania e consumo são complexas (García Canclini, 1995), é importante destacar que há uma tensão importante entre a demanda pedagógica de que a escola abra lugar a diferentes histórias, experiências e saberes, o crescimento da lógica mercantil nas relações políticas e a ocupação do público por essa lógica, e o projeto de educação igualitário, ainda que fosse burocrático. (Dussel, 2018, p. 93, tradução própria) ${ }^{28}$

Helena Altmann (2002) sistematiza alguns elementos do pacote de reformas educativas proposto pelo Banco Mundial à época: (a) prioridade na educação básica; (b) melhoria da qualidade educativa como eixo da reforma; (c) prioridade sobre aspectos financeiros e administrativos; (d) descentralização e autonomia das instituições educativas; (e) convocação para participação da comunidade nos assuntos escolares; (f) incentivo ao envolvimento do setor privado e organizações não-governamentais na educação e (g) enfoque setorial. Um dos resultados dessas medidas foi a fragmentação do sistema escolar e a formação do que Dubet (2011) denomina um "mercado escolar", no qual carreiras, títulos e estabelecimentos competem entre si e as famílias escolhem as disciplinas em função da construção de um capital. ${ }^{29}$

A partir dos anos 2000, uma nova pauta de reformas educativas busca aprofundar as mudanças iniciadas nas décadas anteriores a partir da flexibilização da educação dita "tradicional" e das instituições e da utilização das novas tecnologias no espaço escolar (Banco Mundial, 2003). $\mathrm{Na}$ prática, trata-se de ampliar o mercado educacional abrindo espaço para parcerias públicoprivadas e novas modalidades de ensino, marcadamente à distância, e certificados (Venturini, 2020).

A facilidade e rapidez com que as "parcerias" com empresas tecnológicas globais têm se multiplicado no ensino básico e superior pode ser explicada, assim, a partir de duas perspectivas complementares que serão exploradas em maiores detalhes a seguir. Por um lado, elas respondem a um processo mais amplo de mercantilização da educação no âmbito do neoliberalismo, que naturaliza a aproximação entre escola/universidade e empresas (Dubet, 2011; Laval, 2004). Tal processo implica tanto uma pressão direta e ações concretas que permitam uma maior permeabilidade da educação às lógicas do mercado, quanto uma concepção generalizada de que as soluções empresariais seriam necessariamente mais eficientes que alternativas desenvolvidas pelo Estado ou as mesmas universidades.

Por outro lado, um conjunto de precariedades favorece a expansão das tecnologias do capitalismo de vigilância no âmbito educacional no Brasil. A situação responde a desafios estruturais mais amplos e tem um caráter multifacetado, mas não se pode ignorar o papel das reformas neoliberais empreendidas nos últimos 30 anos na deterioração da infraestrutura tecnológica e educacional públicas.

28 "Si bien las relaciones entre ciudadanía y consumo son complejas (García Canclini, 1995), es importante señalar que hay una tensión importante entre la demanda pedagógica de que la escuela haga lugar a distintas historias, experiencias y saberes, el crecimiento de la lógica mercantil en las relaciones políticas y la ocupación de lo público por esa lógica, y el proyecto de educación igualitario, así fuera burocrático."

29 A mudança observada por Dubet pode ser ilustrada pelo caso estadunidense. Ao retomar brevemente a história das reformas educativas nos Estados Unidos, Larry Cuban (2001) observa como apesar de ser associada ao progresso econômico e à competitividade das empresas nacionais desde o século XIX, a educação nunca havia sido compreendida em função da política econômica e as escolas nunca haviam sido requeridas a operar como corporações. Ao contrário, tinham uma missão cívica e moral que excedia os objetivos de lucro das corporações privadas. Segundo ele, isso se transforma a partir dos anos 80 quando a gestão privada torna-se referência para solucionar os problemas de escolas e universidades. Além disso, elementos escolares passam a diretamente carregar publicidade de apoiadores corporativos. 
Para mencionar alguns aspectos particularmente relevantes ao se pensar o uso de tecnologias na educação básica, adaptando a análise em camadas proposta por Dughera (2015) podemos observar que já na camada de infraestrutura e conectividade se encontram as desigualdades de acesso à Internet, requisito fundamental para qualquer estratégia de ensino remoto. Em relação ao hardware, o acesso a computadores segue limitado e em vem decaindo nos últimos anos no país. Ao mesmo tempo, aumenta o número de pessoas que acessam a rede apenas pelo celular, especialmente entre as classes mais baixas. Nesse contexto, as soluções comerciais desenvolvidas com foco nos dispositivos móveis e, em alguns casos, contando com acordos com empresas de telecomunicações que garantem acesso sem desconto dos planos pré-pagos de dados aparecem como as melhores opções em termos de "software".

Frente a esse cenário, as opções comerciais se apresentam não só como atrativas, mas como inevitáveis. A implementação dessas soluções no âmbito educacional possibilita e justifica o desinvestimento em infraestrutura e gestão da informação em instituições públicas de ensino, assim como no desenvolvimento de soluções que respondam às demandas e contexto locais. $\mathrm{O}$ processo envolve a transferência da capacidade de armazenamento e processamento de dados a servidores externos e a oferta de plataformas supostamente gratuitas para a comunicação. Em troca, se facilita o acesso privado às informações de milhares de docentes e estudantes que serão utilizados para fins desconhecidos ou, no mínimo, opacos para o público.

\subsection{Do desenvolvimento situado à mercantilização}

A influência neoliberal nas propostas e discursos relacionados ao uso de tecnologias no âmbito educativo é inegável e, como vimos, as reformas impulsionadas a partir dessa perspectiva são cruciais para os processos de privatização e mercantilização que se acentuam com a chegada das plataformas do capitalismo de vigilância nas instituições educativas. No entanto, é importante ressaltar o longo histórico de discussões e políticas que buscaram promover tal uso de modo a garantir a melhoria do sistema de ensino público e o fato de que os interesses na inserção de tecnologias na escola (e nas reformas educativas, de modo geral) são diversos e não poderiam ser resumidos à influência de organismos internacionais.

No Brasil, as primeiras experiências de uso de computadores na educação tiveram início nas universidades com estudantes de graduação. O ano de 1971 é tido como um marco por conta da realização de um seminário intensivo ministrado por um especialista da Universidade de Dartmouth, nos Estados Unidos, que discutiu a utilização de computadores para o ensino de física (Valente, 1999). Em 1973, já havia registros de experiências realizadas no ensino superior na área de exatas (química e física) em universidades do Rio de Janeiro e Rio Grande do Sul.

$\mathrm{Na}$ década seguinte, dois programas no Ministério da Educação (MEC) seriam implementados buscando formar professores, promover o desenvolvimento de software educacional nacional e estimular o uso das novas tecnologias na educação básica e superior. Os programas foram desenvolvidos a partir de uma preocupação em desenvolver políticas que tivessem uma real conexão com os interesses da sociedade brasileira e após a realização de dois seminários que tiveram como objetivo consultar a comunidade científica sobre estratégias de planejamento (Moraes, 1997).

Nos anos 90 viria o Programa Nacional de Informática na Educação (ProInfo) com o objetivo de "disseminar o uso pedagógico das tecnologias de informática e telecomunicações nas escolas públicas de ensino fundamental e médio pertencentes às redes estadual e municipal". Ele tem sido constantemente reformulado e complementado por uma série de outras iniciativas nacionais e locais, inclusive voltadas à oferta de conectividade a escolas rurais e urbanas e à distribuição de equipamentos para docentes e estudantes.

A ênfase das primeiras políticas de uso das novas tecnologias na educação básica e pública tinha por trás a defesa feita por alguns dos pioneiros e pioneiras de seu caráter transformador no 
ambiente escolar e sua aproximação da teoria construtivista. Como observa José Armando Valente (1999, p. 7), por uma demanda da própria comunidade acadêmica, "as políticas e propostas pedagógicas de informática na educação, no Brasil, sempre foram fundamentadas nas pesquisas realizadas entre as universidades e escolas da rede pública”. Ele opõe dois usos das tecnologias no ambiente escolar: de um lado para a instrução auxiliada por computador, ou Computer Aided Instruction (CAI), na qual a máquina teria como função a automatização da instrução, atuando como grande armazém e transmissor de conhecimentos; de outro para a complementação, aperfeiçoamento e mudança na qualidade da educação, a partir da possibilidade do uso da máquina no auxílio à resolução de problemas, controle de processos em tempo real, entre outros. Ele também diferencia os objetivos da implementação de políticas de uso de TICs nas escolas brasileiras e nas escolas francesas ou estadunidenses, associando a opção nacional à necessidade de se promover a qualidade do sistema educativo, de modo a situá-la ao contexto brasileiro.

No entanto, a incidência das empresas de tecnologia nas políticas desenvolvidas nesse sentido pode ser identificada ao longo do tempo, uma vez que a educação foi logo entendida como um mercado promissor. Moraes (1997) aponta como já nos anos 80 os incentivos públicos para o desenvolvimento de software nacional sofreram com "interferências de grupos interessados em paralisar a pesquisa em favor de uma possível abertura do 'mercado educacional' de software junto às secretarias de educação".

Larry Cuban observa como - no contexto dos Estados Unidos, mas que pode ser facilmente transposto ao brasileiro - os interesses da inserção das novas tecnologias nas escolas incluem: (i) a obtenção de lucros com a venda de equipamentos, software e conteúdos no mercado educacional; (ii) a solução de problemas que historicamente acompanham a educação; (iii) a revolução das práticas de ensino em sala de aula e (iv) a inclusão digital das camadas mais pobres e minoritárias da sociedade. Um grupo heterogêneo de "reformadores" a partir destes interesses pressionariam, assim, pela inclusão das tecnologias na escola com o objetivo de torná-las mais eficientes e produtivas, o processo de ensino e aprendizagem uma prática ativa e conectada com a vida real e preparar os jovens para o mercado de trabalho (Cuban, 2001).

As soluções oferecidas pelas empresas centrais para o capitalismo de vigilância atuam nesse sentido e contribuem com uma gradual mercantilização das instituições educativas. Como observa Laval (2004) esse processo de mercantilização ocorre de duas formas: a primeira "consiste na estratégia das empresas que querem penetrar no domínio escolar, seja por razões publicitárias (mercado indireto), seja para a venda de produtos (mercado direto)" e a segunda "remete à transformação das escolas em empresas produtoras de mercadorias específicas" (Laval, 2004, p. 113).

Devido à lógica de operação do capitalismo de vigilância ele é capaz de incidir em ambos os sentidos quando consegue desenvolver acordos com instituições educacionais públicas: por um lado impõe suas soluções para uma massa da população que não necessariamente as utilizava, cativando novos consumidores, inclusive desde a infância. Por outro, torna escolas e universidades produtoras de valor, na medida em que facilita o acesso a uma quantidade incalculável de dados que viabilizarão seu acúmulo de capital.

\section{Conclusões}

Evgeny Morozov (2020) aponta que a pandemia de Covid-19 acelerou o que ele chama de solucionismo: as tecnologias digitais são apresentadas como soluções para problemas políticos. Segundo Morozov, o solucionismo digital acompanha as políticas neoliberais. Enquanto o neoliberalismo restringe e diminui o orçamento público, o solucionismo apresenta alternativas, e assim vão reformulando de maneira drástica e acelerada o funcionamento de instituições e governos. Assim, a busca por alternativas a situações de crise é encerrada pela oferta de 
tecnologias apresentadas como inovadoras, seguras e, nos casos das universidades públicas, sem contrapartida financeira - sem a necessidade de um amplo debate sobre as raízes políticas do problema.

No caso da educação, as tecnologias educacionais das empresas de vigilância estão sendo adotadas como solução para um problema que o próprio Estado não consegue resolver: o de manter o semestre letivo a qualquer custo em tempos de distanciamento social. Sem estrutura e sem investimento, as tecnologias digitais - em especial aquelas cedidas "gratuitamente" em troca dos dados coletados - estão sendo acatadas acriticamente como solução para aulas não presenciais.

A situação é particularmente grave considerando que o Brasil possui um histórico de uso pioneiro dessas tecnologias no âmbito educacional a partir de uma perspectiva de promoção da autonomia dos agentes educativos e melhoria dos sistemas públicos. Ao mesmo tempo, se insere em um histórico mais amplo de solucionismo digital no âmbito da educação que remonta as narrativas promovidas por organismos internacionais para justificar suas reformas educativas que se baseiam numa perspectiva de neutralidade das tecnologias. Elas partem de uma lógica tecnocrática segundo a qual a mera inserção das novas tecnologias nas salas de aula determinará uma transformação dos processos pedagógicos ditos ultrapassados e da escola de modo geral (Cuban, 2001).

Como apontado nos artigos "Infraestruturas, Economia e Política Informacional: o Caso do Google Suite For Education" (Parra et al. 2018) e "Coletando dados sobre o Capitalismo de Vigilância nas instituições públicas do ensino superior do Brasil”' (Cruz, Amiel \& Saraiva, 2019), a adoção de tecnologias hegemônicas, assentes na coleta e processamento de dados e metadados, pode gerar consequências amplamente negativas às instituições de ensino, em especial as públicas. Podemos apontar: 1) a adoção impede que as instituições tenham um maior controle e segurança dos dados, que não estão mais sobre seu controle, mas nos data centers das empresas do capitalismo de vigilância; 2) há um sério e não discutido problema relacionado à relação públicoprivado: ao oferecer um serviço público, as instituições inserem compulsoriamente os cidadãos a participarem de um mercado privado, cujo papel desempenhado é desconhecido e muito pouco transparente; 3) ao apoiar o uso de tecnologias hegemônicas, que, na prática, trata-se de privatizar parte de suas atividades de gestão de tecnologias de informação, as instituições públicas de ensino, em especial as universidades - locais privilegiados de produção tecnológica -, deixam de investir na criação de modelos alternativos ao capitalismo de vigilância; 4) da mesma forma, essa terceirização, ao ceder parte do trabalho de gestão em TI aos contratados pelas grandes empresas de tecnologia, deixam de oferecer vagas de emprego aos próprios estudantes das áreas de tecnologia das universidades; 5) privatização dos dados e metadados gerados nas interações educacionais, que dizem respeito ao desempenho individual dos estudantes e dos professores e acaba por ceder às empresas do capitalismo de vigilância dados valiosos sobre a educação pública brasileira, essenciais para a construção de políticas públicas eficientes; 6) por fim, como afirma Williamson (2017), a adoção cada vez mais ampla de tecnologias voltadas à captura de dados acaba por inserir o vigilantismo nos processos pedagógicos, em que o desempenho dos atores envolvidos, em especial estudantes e alunos, é avaliado através da análise de desempenho baseado nos dados capturados por algoritmos.

Além disso, como observamos nesse estudo, essas políticas ocorrem de maneira localizada e pontual a partir de negociações diretas entre as empresas e as instituições públicas - universidades, secretarias de educação ou escolas - de modo a dificultar seu monitoramento. Associada à pressão da opção pela manutenção do calendário escolar, em muitos casos compromete a participação da comunidade acadêmica e escolar nas decisões que orientam sua adoção. Assim, um único setor o privado - parece ter uma influência desproporcional na tomada de decisões de caráter essencialmente público. $\mathrm{O}$ movimento acentua as dificuldades estruturais para o uso de 
tecnologias na educação prévio à pandemia, gerando mais desigualdades tanto no âmbito digital, quanto educativo.

Ao oferecer aplicativos educacionais e espaço em data center para milhares de alunos de escolas e universidade públicas do Brasil, as empresas envolvidas nesse mercado ampliam suas possibilidades de extração da matéria-prima para seus produtos, aumentando seus ativos de vigilância. A interação dos usuários com os aplicativos educacionais e o crescimento do número de estudantes, professores e pesquisadores que necessitam possuir contas - e portanto oferecer dados - nessas plataformas para realizar suas atividades escolares ou de pesquisa nas instituições públicas de ensino faz com que a Google ou a Microsoft, as empresas mais populares no caso brasileira, possam utilizar segundo seus critérios informações referentes à comunicação e desempenho dessas pessoas e da produção de conhecimento do país.

Como apontam nossas pesquisas, frente a um sustentado processo de desinvestimento em infraestrutura local e desenvolvimento tecnológico e de aceitação acrítica de um discurso que defende que qualquer tecnologia necessariamente representaria melhorias na educação, as tecnologias digitais do capitalismo de vigilância são apresentadas aos gestores das escolas públicas como única solução. Essa dupla ação sobre a gestão pública aparece, para esse modelo de negócio, como uma grande oportunidade de se apropriar de um imenso conjunto de dados que, até então, não estavam sob seu domínio e aprofundando, assim, os fluxos de capital, conhecimento e trabalho do capitalismo global, dos países do sul aos países do norte do globo.

A entrada desses sistemas no âmbito educacional implica na exposição obrigatória de um novo público a um modo de pensar e operar que não necessariamente condiz com as melhores práticas pedagógicas, as diretrizes curriculares brasileiras ou as demandas docentes. Nesse sentido, abre-se espaço para mais uma camada de silenciosa mercantilização da educação pública e perda de autonomia docente que, por todo o exposto, não deve retroceder facilmente após a pandemia. A preocupação vai muito além da publicidade personalidade e privacidade individual. Há uma série de impactos sociais e coletivos implicados no avanço do capitalismo de vigilância que seguem em grande medida invisíveis e têm a ver com o tipo de sociedade que queremos construir.

\section{Referências}

Altmann, H. (2002) "Influências do Banco Mundial no projeto educacional brasileiro", em Educação e Pesquisa, 28(1), p. 77-89. São Paulo. doi: 10.1590/S1517-97022002000100005 [GS Search]

Banco Mundial (2003). Aprendizaje permanente en la economía global del conocimiento: desafíos para los países en desarrollo. Colombia, Banco Mundial e Alfaomega Colombiana. [GS Search]

Cruz, L. Amiel, T. Saraiva, S. Coletando dados sobre o Capitalismo de Vigilância nas instituições públicas do ensino superior do Brasil. In: 2019, Salvador. Anais do . In: LAVITS. Salvador: LAVITS, 2019. Disponível em: http://lavits.org/wpcontent/uploads/2019/12/Cruz_Saraiva_Amiel-2019-LAVITS-1.pdf [GS Search]

Cuban, L. (2001) Oversold and underused: Computers in schools 1980-2000. Cambridge, Harvard University. [GS Search]

Dubet, F. (2011) Repensar la justicia social: contra el mito de la igualdad de oportunidades. Buenos Aires, Siglo Veintiuno Editores Argentina.

Dughera, L. (2015) "Una propuesta posible acerca de cómo analizar la incorporación de planes 'una computadora, un alumno' en la institución educativa”, em LAGO MARTÍNEZ, S. 
(coord.) De tecnologías digitales, educación formal y políticas públicas. Aportes al Debate. Buenos Aires, Teseo. [GS Search]

Dussel, I. (2018) "Sobre la precariedad de la escuela”, em LARROSA, J. B. (ed.) Elogio de la Escuela. Buenos Aires, Miño y Dávila Editores.

Evangelista, R. (2019) Review of Zuboff, Shoshana. 2019. The Age of Surveillance Capitalism: The Fight for a Human Future at the New Frontier of Power. Surveillance and Society, Vol 17 No 1/2 (2019).

Laval, C. (2019). A escola não é uma empresa: o neoliberalismo em ataque ao ensino público. Boitempo Editorial. [GS Search]

Lindh, M., \& Nolin, J. (2016). Information We Collect: Surveillance and Privacy in the Implementation of Google Apps for Education. European Educational Research Journal, 15(6), 644-663. doi: 10.1177/1474904116654917 [GS Search]

Madden, M., Gilman, M., Levy, K., \& Marwick, A. (2017). Privacy, poverty, and big data: A matrix of vulnerabilities for poor Americans. Wash. UL Rev., 95, 53. [GS Search]

Moraes, M. C. (1997) "Informática Educativa no Brasil: uma história vivida, algumas lições aprendidas", em Brazilian Journal of Computers in Education, v. 1, n. 1, p. 19-44. [GS Search]

Morozov, E. (2019) Capitalism new clothes. thebaffler.com. Disponível em https://thebaffler.com/latest/capitalisms-new-clothes-morozov

Morozov, E. (2020). Solucionismo, nova aposta das elites globais. Outras Palavras. Disponível em https://outraspalavras.net/tecnologiaemdisputa/solucionismo-nova-aposta-das-elitesglobais/

NIC.BR. (2020) Pesquisa sobre o uso das tecnologias de informação e comunicação nas escolas brasileiras: TIC Educação 2019. São Paulo, Comitê Gestor da Internet no Brasil.

Parra, H. Cruz, L. Amiel, T. Machado, J. (2018) Infraestruturas, economia e política informacional: o caso do Google Suite for Education. Mediações - Revista de Ciências Sociais, Londrina, v. 23 n. 1, p. 63-99, Jan./Jun. 2018. doi: 10.5433/2176$\underline{6665.2018 \mathrm{v} 23 \mathrm{n} 1 \mathrm{p} 63}$ [GS Search]

Rouvroy, A. e Berns, T. (2018) "Governamentalidade algorítmica e perspectivas de emancipação: o díspar como condição de individuação pela relação?” em BRUNO, F. et al. Tecnopolíticas da vigilância: Perspectivas da margem. São Paulo, Boitempo. [GS Search]

Valente, J. A. et al. (1999) O computador na sociedade do conhecimento. Campinas, Unicamp/NIED. [GS Search]

Venturini, J. (2014) Recursos educacionais abertos no Brasil: O campo, os recursos e sua apropriação em sala de aula. São Paulo, Ação Educativa. [GS Search]

Venturini, J. (2020) Educação, liberdade e tecnologias: usos de conteúdos digitais por professores da educação básica no Brasil. 2020. Dissertação (Mestrado em Ciências Sociais com Orientação em Educação) - Faculdade Latino-americana de Ciências Sociais (Flacso), Buenos Aires, 2020. Disponível em: http://hdl.handle.net/10469/16376. Acesso em: 202010-08. [GS Search]

Venturini, J., Louzada, L., Maciel, M., Zingales, N., Stylianou, K., \& Belli, L. (2019) Termos de uso e direitos humanos: uma análise dos contratos das plataformas online. Rio de Janeiro: Revan. [GS Search] 
Williamson, B. (2017). Big Data in Education: the Digital Future of Learning, Policy and Practice. London: SAGE. [GS Search]

Zuboff, S. (2018) "Big Other: capitalismo de vigilância e perspectivas para uma civilização de informação" em BRUNO, F. et al. Tecnopolíticas da vigilância: Perspectivas da margem. São Paulo, Boitempo. [GS Search]

Zuboff, S. (2019). The Age of Surveillance Capitalism: The Fight for a Human Future at the New Frontier of Power. New York: Public Affairs. 